\title{
Teaching Translation and Interpreting through Fiction
}

\author{
Dong-mei Ma \\ College of Foreign Languages and Cultures \\ Sichuan University \\ Chengdu, China \\ meredith310@126.com \\ Foreign Language School of Lanzhou University of Technology \\ Lanzhou, China
}

\begin{abstract}
This paper aims to put forward a new and interesting method to teach translation theories for future translators and interpreters. Since the study of translation theory is necessary for translator and even interpreter training, the internalization of translation theory is a crucial step and can be served as a basis for students to develop their own unified theory. The research in this paper advocates develop a teaching methodology to help students internalize the theory they learn in class. The research uses empirical approach to suggest that teaching translation theory through fiction is an effective way for instructors' teaching and students' internalization of translation theory because the narratives and plots in fiction can offer students unique opportunities for reflection. These reflections can be more insightful than those associated with what specialists tend to classify as "real theory".
\end{abstract}

Keywords-Internalization; Translation theory; Translator and interpreter training; Fiction

\section{INTRODUCTION}

Translation researchers, practitioners or teachers often asked themselves the question "Is the study of translation theory necessary for the practice or teaching of translation?" For many times, they felt the question heavy in the air, light on the tip of somebody's tongue, or nagging at the back of their own mind [1]. However, Literature on translation studies abounds in arguments for the guidance role of translation theory for translation practice. Many people have written on the pedagogical values of translation theory. For example, Gentile believes that "practice which is not informed by a theoretical framework suffers from the idiosyncrasies of practitioners, reduces the teaching of the skills to a regurgitation of recipes and the practice to a concern for the personal qualities and authority of the practitioner" [2]. Such ideas are shared by many other scholars of translation studies as well. For example, Mu Lei once discussed the relationship between translation theory and translation practice. She said that even many instructors didn't realize the importance of translation theory in helping the students improve their translation competence, and thus not giving full recognition of the significance of teaching translation theory in teaching translation and interpreting [3]. Many scholars have defined translator or interpreter competence from different perspectives. Catherine Way once defined translator and interpreter competence as composed of communicative and textual competence, cultural competence, subject area competence, instrumental and professional competence, psychophysiological or attitudinal competence, interpersonal competence and strategic competence [4]. Margherita Ulrych defined translator or interpreter competence as translation competence, methodological competence, disciplinary competence and technical competence [5]. Liao Qiyi discussed the role played by translation theory in training of students of MTI and contended that "no matter in what way we define the translator or interpreter competence, the study of translation theory is an indispensable part of translator or interpreter training [6]. Now it is clear that to be a qualified translator or interpreter, the study of translation theory is necessary. In fact, translation theory is included in translation curriculum and translation theory does figure in some syllabi. However, many students complained that the theories are too abstract to give them any useful guidance in their actual translating. Therefore, an appropriate methodology must be framed to help the students internalize the theory they have learned.

\section{BRIEF REVIEW Of METHOdOLOGIES IN TEACHING TRANSLATION THEORY}

Many instructors and researchers have attempted to frame methodologies in teaching translation. One of the main approaches is reflective journal writing. This approach has been widely used in language teaching and teacher education as a powerful device to promote students' thinking and learning since the early 1980s. Li De-feng introduced reflective journals in teaching Commercial Translation at the Chinese University of Hong Kong. He summarized the advantages of reflective journals as follows: Firstly, it draws students attention to the process of translation; secondly, students can experience how theory learned in class can inform their decision making in translation [7]. Vivian Lee also looks at the role of the reflective learning journal by presenting students' perspectives of a semester-long assignment given to firstsemester interpreting and translations studies postgraduate students for their Korean into English translation practice class [8]. 
Another approach drawing wide attention is the proposal of "whole-person translator education". In the early period, translators were more trained than educated as translators and interpreters were taught informally, basically through trial and error, or through any of the various translating activities that accompany the study of a foreign language and culture within the Liberal Arts tradition. However, it becomes more and more demanding to be a qualified translator or interpreter in the new era. Therefore,

it is important to make a distinction between translation teaching as training and as education, with the former emphasizing the teaching and learning of translation skills and techniques, whereas the latter on a more holistic development of the students' overall intellectual and academic well-being. To our mind, real success for a university translation program lies in its full recognition that translation teaching at the tertiary level is neither training alone nor education in abstraction, but it is both training and education [9].

As for the goals of translation education in universities, Kiraly stated as follows:

The primary goals of translator education include raising students' awareness of the factors involved in translation, helping them develop their own translator's self-concept, and assisting in the collaborative construction of individually tailored tools that will allow every student to function within the language mediation community upon graduation [10].

After giving a historical survey of Chinese translation teaching, Tao Youlan proposed the idea of whole person translator education in translation pedagogy. She suggested that translation education in China must pay more attention to the following aspects: 1) The integration of translation theories and other interdisciplinary theories into translation teaching; 2) The integration of joint perspectives from professionalism and academia into the curriculum; 3) The integration of technology into translation teaching; 4) Co-existence of various forms of translator education; 5) Training of trainers (teachers); 6) Promoting "whole-person translator education" [11].

The efforts made by these scholars and researchers benefit a lot for the enhancement of translation teaching. The author in this paper made another attempt, so to say, to teach translation through fictional works, such as movies, motion pictures and fictions. The use of fictional representations of translation for pedagogical purposes has been addressed by Michael Cronin in his study of film and translation. Michael Cronin once incorporated cinema into the teaching of translation. He maintained that movie is a highly engaging and effective medium for soliciting responses from students on a wide variety of topics directly related to the business of translation.

\section{TEACHING TRANSLATION THROUGH FiCTION}

Rose Mary Arrojo once incorporated the reading of certain fictions of which themes are translation-related issues into translation teaching by maintaining that engaging storylines can obviously count on the appeal of fiction's creative resources-colorful, contradictory characters, humorous or unpredictable intrigues, surprising events and revelations, dramatic twists and turns- they are quite efficient in enticing non-specialists to begin probing some of the theoretical concerns that have defined the practice of translation and captured the attention of scholars [12]. Fiction is the focus of the author's course design. Authors and Affiliations

\section{A. Course Objectives}

The specific course is intended for students who are of the introductory level in studying translation and interpreting and who are required to study basic theories concerned with the nature of translation, the skills and techniques of translating and the actual work and situation of translators. These theories are introduced by means of reading certain fictions assigned by the instructors instead of reading the so-called serious theoretical works. After reading the assigned fictions, the students become familiar with the characters and the storylines. Then the instructor can guide the students to relate the characters and storylines to the real translation facts. Of course, this does not mean replace the study of theoretical works with fictions, which can only serve as complementary hand in our teaching.

\section{B. Couse Design}

The course is intended to incorporate the reading of fictions into the introducing of translation theories for a semester-long assignment given to first-semester interpreting and translations studies for their translation theory and practice class. For the beginners who first get in to contact with the translation theories, the works of the philosophers and scholars may seem abstract, boring and even unreadable, so to motivate their interest is very important. Reading fiction instead of theoretical works may be an effective way. The author planned six novels by Jorge Luis Borges, Borges, Italo Calvino, Julio Cortazar, Issac Babel, Jose Saramogo respectively for the students to read. These novels are common in that they all use translation as the theme. Each one of them will be analyzed in combination with one of the regularly discussed issues in translation studies. Therefore, before reading the story, the teacher will give the students some guidance for them to discern the metaphor or fictional representations of translation. This may help the students familiarize themselves with the key theoretical notions and deepen their understanding of these notions. 


\section{A Case Study With Rodolfo Walsh'S Footnote}

Footnote is in fact a suicide letter by a lonely and unhappy translator Leon de Sanctis who just killed himself in the cheap boarding house where he lived. He was a striving manual laborer in a tire shop at first. He saw the career translation as privileged and thought that it can promise him a better life away from poverty and the rigors of manual labor, so he worked hard to study English to become a translator as he long dreamed. With great enthusiasm he began his career as a translator. However, he found everything totally different from what he imagined. Firstly, he cannot choose the work he liked to translate or the way of translating either. Only the editor holds the exclusive power to establish what can be read and how it should be translated while the subservient translator is expected to be invisible and blindly serve the publisher's interests. The protocols of the profession are generally defined by those who commission rather than those who actually produce translation. What's more, he found it more painful to be a translator than a laborer in the tire shop because to be a laborer one only needs to lend ones hands to the employers, but to be a translator one has to lend both one's head and hands to a stranger. He felt he was an imbecile who was worn out, empty, devoid of ideas. Secondly, he wished to better off his life by entering into a new career which seems to be more privileged. However, he soon found that he worked more hours and made less money than he did fixing tires. After having translated one hundred and thirty books for the publishing house, all he had was two outfits, one pair of shoes and an old dictionary. In the end, alone and physically and emotionally drained after years of continuous hardship and total dedication to an activity of which he could no longer be proud, Leno decides to end his life. Before he killed himself, he wrote this letter to his editor Otero who was reluctant to open the translator's letter and imagined his own version of the letter. So Footnote is composed of two narratives: the main body and footnote. The main body of the text is the Otero's imagined version of the dead man's letter while the translator's own version is put in the place of footnote.

Step 2 Help the Students Identify the Fictional Representations of Translation

After summarizing the storylines of the novel and analyzing the situation of the character, the teacher can guide the students to find out the metaphors in the novel. First, through Walsh's stirring characterization of the translator as a subservient laborer who is forced to repress his creativity students can have an idea of the restrictions the translator may be faced with in real work situation. Walsh's vivid depiction of the physical and mental misery suffered by the translator may be more convincing than any serious works of theory. Second, Walsh put the narration of the translator in the place of footnote while putting the imagined version by the editor in the main body of the text, which is indicative of the marginalized position of the translator and translated works usually receive in real situation. What Walsh does seems to be similar to that of some cotemporary translation studies scholars who are committed to a form of theory. Therefore, the teacher can stimulate the students to relate the story with the issue visibility vs invisibility of translators in translation studies.
Step 3 Study the Translation Related Issues in Combination with the Study of Theoretical Works

It is widely known that the translation theorist Lawrence Venuti is concerned with one the central focuses of contemporary translation studies----the recognition and exploration of the translators' visibility. He addressed this issue in his well-known book The Translator's Invisibility----A History of Translation by which he intends to expose the scandals of translation. According to him, the greatest scandal of translation is the "asymmetries, inequities, relations of domination and dependence exist in every act of translating, of putting the translated in the service of the translating culture" [13].

Similarly, many Chinese translation theorists such as Xie Tianzhen also showed concern about the problem of the visibility and invisibility of translators. Some translators such as Dong Leshan once talked about the marginalized position and lower pay received by translators.

Although Footnote by Walsh and these scholarly works by Venuti and other theorists belong to different genres, one being fiction and the other being scholarly texts, they in fact addressed the similar issues and even lead to the similar conclusion. They both addressed the problem of the marginalization of translators and translations and the absurd demands imposed on the translator by the publishing house. The reading of story can make the students more interested in translation theory and enrich their understanding of scholarly texts on the topic, which can serve as a basis for them to get a comprehensive and objective understanding of their possible future job. Besides, as we know that fiction is always treated a multilayered network of texts and textual relations, Footnote offers the students a portrait of the translator that is also multilayered, which is more complicated than the one we find in theoretical works. Therefore, as Arrojo suggests, "students are likely to get more involved with characters and be more personally touched or impacted by them and what they represent than by the sound, rational arguments of our most lucid theorists"[14].

\section{CONCLUSION}

As a complement for the conventional teaching procedures, reading of fiction in translation and interpreting teaching proves to be efficient in the following ways. Firstly, it can greatly elicit the students' interests by the vivid storylines. Secondly, it can familiarize the students with the issues that are usually neglected in the so called reasonable works. The students can make comparisons in the way the different genres address the same issues and develop their own ideas. In addition, fiction as a resource not only has an immediate resonance for student translators and links directly to their own intertextual competence, but also greatly broadens the range of potential materials at the disposal of the teacher or instructor. The reading of fiction on the theme of translation, rather than merely confirming or echoing the arguments and conclusions of philosophers and translation studies scholars, can illuminate certain issues that are rarely explored in more conventional scholarship. Borrowing and adapting Michael Cronin's words, "neglecting to use fiction in translation studies and translation 
teaching is neglecting to use a highly engaging and effective medium for soliciting responses on a wide variety of topics directly related to the business of translation [15]. The author hopes that this research can throw interesting light on the difficulties facing those who found the theories are too abstract to be internalized and put into practice.

\section{ACKNOWLEDGMENT}

Supported by Research Project of Higher Education Institutes in Gansu Province (2016A-015)/ 2016's Provincial Educational Science Program during 13th Five-Year Plan Period in Gansu Province (GS[2016]GHB0237)/2017's English Teaching Reform Program co-sponsored by Gansu Higher Education Institutes and Shanghai Foreign Language Education Press (2017(37))

\section{REFERENCES}

[1] Zhu Chun-shen, "Translation: Theories, Practice and Teaching," In Eva Hung (eds.) Teaching Translation \& Interpreting 4. Amsterdam \& Philadelphia: John Benjamins, 2002, p. 19.J. Clerk Maxwell, A Treatise on Electricity and Magnetism, 3rd ed., vol. 2. Oxford: Clarendon, 1892, pp.68-73.

[2] A. Gentile, "The Application of Theoretical Constructs From a Number of Disciplines for the Development of a Methodology of Teaching in Interpreting and Translating," Meta, 1991, vol.36 (2-3), pp.344-351.

[3] Mu Lei, "The Importance of Translation Theory in Translation Teaching," Foreign Languages and Their Teaching, 2004, pp. 43-46.

[4] C. Way, "Systematic Assessment of Translator Competence: In Search of Achilles' heel," In John Kearns (ed.), 2008, p.91.

[5] M. Ulrich, “Training Translators: Programmes, Curricula, Practices," In Martha Tennent (ed.), 2005, p.18.

[6] Liao Qi-yi, "Teaching of Translation Theory in MTI," Chinese Translators Journal, 2011, pp. 25-28.

[7] Li De-feng, "Reflective Journals in Translation Teaching," Perspectives: Studies in Translatology, 1998, vol. 6 (2), pp. 225-234.

[8] V. Lee, "A Model for Using the Reflective Learning Journal in the Postgraduate Translation Practice Classroom," Perspectives: Studies in Translatology, 2015, vol. 23 (3), pp.489-505.

[9] Tan, Z, "Towards a Whole-Person Translator Education Approach in Translation Teaching on University Degree Programmes," Meta: Journal des Traducteurs, 2008, vol. 53 (3), pp. 589-608.

[10] Kiraly, D, “A Social Constructivist Approach to Translator Education: Empowerment from Theory to Practice," Manchester and Northampton: St. Jerome Publishing, 2000, p. 49.

[11] Tao You-lan, "Translator Training and Education in China: Past, Present and Prospects," The Interpreter and Translator Trainer, 2016, vol. 10 (2): 204-223.

[12] R. Arrojo, "Fictional Translators-----Rethinking Translation through Literature," Routledge: London \& New York, 2018, p.5.

[13] L. Venuti, "The Scandals of Translation-Towards an ethics of Difference," London: Routledge, 1998, p. 4.

[14] R. Arrojo, "Fictional Translators-Rethinking Translation through Literature," Routledge: London \& New York, 2018, pp.45-46.

[15] M. Cronin, "Translation Goes to The Movies," Shanghai: Shanghai Foreign Language Education Press, 2009, p.xix. 